\title{
CUADERNA OSCURA (2018) DE JUAN HERRERA
}

\author{
Yenny Ariz Castillo \\ Universidad Católica de la Santísima Concepción \\ Doctora en Literatura Latinoamericana. Académica del Departamento de \\ Ciencias del Lenguaje y Literatura, UCSC \\ yariz@ucsc.cl
}

$\mathrm{E}$

tercer poemario de Juan Herrera ${ }^{1}$, Cuaderna oscura, forma parte de la colección "Eclíptica" de la editorial penquista Ediciones del Archivo $^{2}$. Si bien el nombre de la obra evoca a la cuaderna vía, el cuarteto monorrimo de versos alejandrinos vinculado a temas religiosos, distintivo del mester de clerecía, no está demás reparar en otros alcances semánticos de "cuaderna": en relación con los navíos, la cuaderna corresponde a una pieza de la quilla de un buque; en cuanto a significados vinculados con su etimología -el latín quaterna, "de cuatro en cuatro"- remitía en la antigüedad a la cuarta parte de alguna cosa, "especialmente el pan y el dinero" (RAE, 1817, p. 256); asimismo, en el medievo, una cuaderna corresponde a una pareja en el "juego de tablas", entretención descrita por Alfonso X “el Sabio" en el Libro de los Juegos [1283] (Castro, 2007). En el juego intervienen dos jugadores o dos "cuadernas", que se esfuerzan por eliminar sus fichas antes que el equipo rival. Además, cuaderna es una antigua moneda española, sujeta a la idea de doble de cuatro, pues corresponde a ocho maravedís.

En su ensayo Arte y belleza en la estética medieval (2012), Umberto Eco aborda las estéticas de la proporción y la relevancia de los números

${ }^{1}$ El autor ha publicado Superfashion (1996) y Ur (2001); por esta última obra recibió el Premio Nacional Dolores Pincheira de la Sociedad de Escritores de Chile, Concepción.

${ }^{2}$ Es el tercer volumen de esta colección, dedicada a la poesía; el primer volumen es Escombros americanos, de Ítalo Nocetti, y el segundo, Ciudades de agua, de Marta Contreras; ambos fueron publicados el 2018. 
en ellas; en relación al poemario de Herrera, cobra sentido la teoría del "homo quadratus" (pp. 64-67), derivación de las cosmologías pitagóricas, en la cual cada número es simbólico en tanto articula correspondencias estéticas. Eco puntualiza que el número cuatro se vinculaba al orden de la naturaleza, al ser humano y a la moral, estableciéndose correspondencias entre estos ámbitos:

El número cuatro se convierte de este modo, en otros autores o en la creencia común, en un número gozne y resolutor, cargado de determinaciones seriales. Cuatro los puntos cardinales, los vientos principales, las fases de la luna, las estaciones, cuatro el número constitutivo del tetraedro timaico del fuego, cuatro las letras del nombre ADAM. Y cuatro será, como enseñaba Vitrubio, el número del hombre, puesto que la longitud del hombre con los brazos abiertos corresponderá a su altura dando así la base y la altura de un cuadrado ideal. Cuatro será el número de la perfección moral, de suerte que tetrágono será denominado el hombre moralmente válido (pp. 65-66).

La Cuaderna oscura de Herrera actualiza los sentidos enunciados: constituye un viaje de abandono de lo conocido, la ciudad, y de búsqueda por la geografía de la escritura y del cuerpo, así como también una travesía por la cultura medieval; desde esta perspectiva el signo "cuaderna" funciona como el soporte o navío de ese viaje. El poemario desarrolla además diversos diálogos con interlocutores mudos, ante quienes la voz poética asume el rol de contrincante o denostador en un intermitente juego de roles. Con respecto a la acepción de "ser una cuarta parte de algo", la estructura del volumen ilustra este significado: el poeta ha distinguido cada texto con un número romano, los plantean que existe un contenido material de la cuaderna y uno hipotético, en el marco del cual un indeterminado número de poemas se oculta a los lectores.

El primer poema corresponde al número XLIV y el segundo al I, lo que podría inducir a creer que se ha comenzado por el final, sin embargo, el seguimiento de las cifras demuestra la ausencia de muchos guarismos, por ejemplo, no figuran poemas con los números VI al X. A pesar de ello, no se trata de un caos numérico, ya que a partir del I, los textos se ordenan correlativamente hasta el LX, con la consabida falta de algunos números. Esto nos sugiere la existencia de dos cuadernas, una explícita, y una segunda, sugerida a partir de los números ausentes, quizás la verdadera cuaderna 
oscura, quizás los otros cuartos de esta cuaderna.

El ocultamiento de poemas, o el vacío debido a los números omitidos, si se prefiere, recupera el mundo de la herencia de las bibliotecas medievales incompletas, a causa de la censura o de los avatares del destino, en la que tan importantes son los incunables preservados como aquellos de los cuales tenemos una idea, un título, o una leyenda. Famosa es la historia del supuestamente extraviado segundo libro de la Poética de Aristóteles dedicado a la comedia, ubicado en un monasterio medieval por Umberto Eco en su novela El nombre de la rosa; no menos conocida es la condición incompleta del manuscrito del Cantar del Mío Cid, cuyos primeros folios jamás se recuperaron. Estos silencios o vacíos de la tradición literaria, algunos sin razón aparente en los que, se conjetura, la historia se supeditó al azar, son plasmados en Cuaderna oscura a través de la aparición de algunos textos y la desaparición consciente de otros.

De este modo, se evidencia la cuaderna manifiesta y la cuaderna oculta. Se distinguen aun una tercera y cuarta cuadernas, que permiten reunir las cuatro partes: la recreación de la "cuaderna vía” como un medio de plasmar una lucha constante con lo sagrado, con Dios y con la moral; y el "cuaderno", soporte de la escritura que proviene etimológicamente de quaterna porque en su origen este reunía cuatro pliegos; sin embargo, en el poemario se ha feminizado como "cuaderna", lo que sugiere la imagen de la mujer como soporte escritural: "En Cuaderna oscura, una presencia femenina atraviesa el texto y toma diversas manifestaciones. La escritura surge entonces como un diálogo con una feminidad sacra- ¿la escritura?- y maldita”, señala Gloria Sepúlveda (2018, s.p.) no solo a propósito de los versos, sino de la portada del libro, imagen de Santa Águeda de Catania. ${ }^{3}$ Los versos corroboran la inscripción de la escritura en diversos cuerpos de mujeres, evocadas desde la nostalgia o el resentimiento. De las cuatro "cuadernas" se despliegan una cantidad indeterminada de dobles: cuaderna luminosa-cuaderna-oscura, Dios-el hombre, lo medieval-lo postmoderno, lo celeste-lo terrestre, lo elevado-lo bajo, las denostaciones-los elogios, los textos incunables-los textos multimedia, lo cómico-lo serio, el lenguaje

${ }^{3}$ Sepúlveda formula interesantes sentidos del texto, entre los que destacamos la lectura del poemario como una Hyponémata, una de las "tecnologías del yo" distinguidas por Michel Foucault. 
religioso-el lenguaje obsceno, el cuerpo-el alma, lo permitido-lo censurado, lo conocido-lo oculto, y se podría continuar.

El conjunto de poemas I al XI evoca lo carnavalesco medieval; previo a estos en la organización del volumen se encuentra el poema XLIV, que enuncia la salida de la voz poética desde la ciudad hacia un camino indeterminado, tránsito hacia una primera estación, el poema I, portador de preguntas sobre la naturaleza y los efectos de la risa, entre los que encontramos aspectos pedestres como exhibir las caries o el sarro al reír y aspectos metafísicos o espirituales: "Que profundidad adquiere en el lamido del abismo / Mas allá de los labios" (p. 2).

Es decir, este viaje se inicia con una carcajada. Pero de la risa el poemario nos traslada al miedo, y de la boca hacia los ojos, pues en el poema II la voz poética conmina a un tú que permanece en el anonimato, tal vez su compañero o su rival en la cuaderna: "Teme de mí porque vi el ojo de dios" (v.1, p. 3). El trasfondo bíblico del verso es doble: por una parte, el ojo de Jahvé lo ve todo y protege a quienes le temen (Salmos 33:18-19), por otra parte, quienes han visto a Jahvé se consideran muertos en la cultura hebrea, como lamenta el profeta Isaías luego de vivir una experiencia sobrenatural en la que cree haberlo visto (Isaías 6:5). Las connotaciones espirituales del verso 1 que desde la tradición judeo-cristiana revisten a la voz poética de un poder singular, se plasman en imágenes sobre el acto de escribir: "Teme de mí / Porque escupo fuerte en los papeles débiles" (vv.78, p. 3), y sobre el cuerpo masculino: "Teme de mi lengua, de las estrías de mi glande" (v.1o, p. 3). La experiencia de ver el ojo de dios implica una separación del interlocutor mudo, al que la voz poética ordena: "Véndate los ojos" (v.12).

El poema III se enfoca en las deposiciones y en el seguimiento del acto de excretar; a partir de un tono solemne y a la vez sarcástico, se unen la materialidad o "lo bajo" con lo espiritual o "lo elevado", en tanto se dice de las heces: "Bésala como a tu madre porque conoce tus entrañas / Ella sabe de qué fermentos estás hecho" (vv.13-14, p. 4). Luego, el poema IV versa sobre la contemplación del ano, figura que se multiplica en diversas imágenes que connotan la oscuridad interna o el reverso del ser humano; como hendidura que comunica los mecanismos internos del cuerpo, el ano "Escupe" (v.9, p. 5), tal como el poeta sobre los papeles. En el poema V la oscuridad se focaliza en pozos negros con gusanos, imagen que se poetiza 
como "una luz que no es oscura" (v.1, p. 6), lo que mantiene la dialéctica entre la oscuridad y la luz.

Enseguida, el poemario plasma el silencio, pues permanecen ocultos -O no existen- los poemas VI al X; en el XI se presenta la materialidad de la muerte sin eufemismos a partir de imágenes como las moscas, el panteonero, el ataúd, hasta llegar a la desintegración, que en el poema se representa en el verso final: "No" (v.15, p. 7). Dos poemas omitidos y luego, el poema XIV escenifica un vacío mental y la voluntad de permanecer en tanto materia, sin la utilizar la razón; en el poema XV se esboza un conflicto con el acto de escribir; la voz poética no se reconoce en sus palabras, pues la materialidad de la escritura persiste mientras el sujeto desaparece ¿̇ha muerto?, ¿nos habla desde ultratumba? Se percibe una conciencia de la fragilidad del ser humano frente al tiempo, en contraste con la permanencia de las palabras.

Tercer silencio de los inexistentes XVI y XVII y se suceden los poemas XVIII hasta el XXIX sin omisiones; en este último se vislumbra una reflexión sobre el acto de escritura y la desintegración del lenguaje y del sujeto que escribe. En el XVIII un asesinato se analoga a la novena sinfonía de Beethoven; el texto se enuncia hacia una segunda persona, a la que se denomina "Hermano" (v.2, p. 10), quien es conminado a cometer, tal vez un asesinato o tal vez suicidio, mientras escucha la clásica pieza musical.

El breve poema XIX "Verdadera caverna el verbo en la cuaderna / Lastre de lenguaje está la lengua entre colgajos" (p. 11) remite tanto a la oscuridad de la palabra y a sus significados como a la desintegración de la lengua proyectada en las aliteraciones verdadera-verbo, caverna-cuaderna, lastrelenguaje-lengua-colgajos. La palabra se potencia en sus aspectos fónicos, mientras que su verbo (significado) se vuelve críptico. Recuérdese que en la tradición judeo-cristiana el verbo corresponde a lo divino (San Juan 1:1) y a su vez, lo divino se asocia a la luz, mientras que en el poemario, los elementos se identifican con su contrario, por ejemplo, la luz con la oscuridad.

Otra versión de la oscuridad se plantea en el poema XX, esta vez es un tubérculo enterrado, pero con el objetivo de impedirle crecer; la anulación de la semilla implica la negación de la transformación y, por lo tanto, de toda vida posible: "Acéptalo en la medida de tu carne que también será enterrada” (v.23, p. 12). De este modo, en Cuaderna oscura encontramos semillas, seres humanos y poemas en la oscuridad. El tubérculo podría 
equivaler al poema silenciado, así como también contraría a la voluntad divina, que condenó a quien ocultó su talento en la tierra (San Mateo 25:1430). En este sentido, el poemario pulsa hacia el Thanatos, el reverso de la luz y de la vida.

Es así como el poema XXI convoca al Eros, pero la voz poética -el amante- se asimila a la figura del panteonero, la que reaparece para divagar sobre las (im)posibilidades de amar, la soledad y el vacío. Mientras en el poema XXII la voz poética declara su inexistencia o su potencial existencia - "Extremo de sal carne versátil no he sucedido" (v.1, p. 15) - los poemas XXIII, XIV, XXVIII y XXIX remiten a los avatares del amor y de la ausencia. En el poema XXIX se traza un triángulo en el que un tú llamado Señor puede traer de vuelta el objeto de deseo de la voz poética con ciertas condiciones que conducen a la subyugación a aquel señor, pero también a la obtención del deseo y a la salvación. La voz poética discurre aceptar esa transformación, pero no se resuelve, solo lo sugiere como posibilidad: "Si diera mi vida a ti / si ese es tu deseo / Traerías su sudor devuelta a mi sábana" (vv.1-3, p. 22).

El poemario escenifica la inercia como un rostro del vacío. El poema XXV acentúa una percepción apática de la existencia: "En esta fábula no hay acción dolorosa / Ya no queda / Nada más que la iteración de lo cansinamente repetido / Exceso de vacío y sequedad en las palabras" (vv.1013, p.18). La repetición de sonidos desemboca en la desaparición del signo como tal y por tanto en la carencia de comunicación, lo que en el poema XXVI constituye motivo de desencanto para la voz poética: "Malentiendo la expresividad del poema /Que malentiende mi inexpresividad / Compartida frustración por el lenguaje...” (vv.1-3, p. 19). En contradicción con esta percepción de los sonidos, la poetización de la voz del norteamericano Tom Waits en el poema XXVII conlleva la valoración de los sonidos y de la palabra como una señal de existencia; aunque la voz poética preferiría "una voz más fina y templada" (v.21, p. 20) que la de Waits, los sonidos emitidos conducen a la existencia.

El siguiente conjunto de textos va desde el poema XXXI hasta el poema XXXVI, en los que el cuerpo masculino se recrea como un espacio fusionado con la ciudad; en el poema XXXI esta ha ingresado al cuerpo de la voz poética, en contraposición, acotamos, al cuerpo como habitación del Espíritu Santo (1 Corintios 6:19); el hablante inicia una purificación de las 
huellas citadinas: el vodka, la comida, los cigarrillos, los gritos de niños y de mujeres. La ciudad, de estructura barroca, se asocia a la violencia (poema XXXII, p. 24); la imagen desolada de una casa vacía y sin puertas se convierte en la casa de la escritura en el poema XXXIV (p. 31).

Una reescritura de las promesas bíblicas vinculadas a la obediencia se realiza en el poema XXXV, pero desde un yo colectivo que se siente ajeno a los favorecidos por las promesas de bendición y, amenaza con dañarlos: "Llevaremos el frío a su clan cada día / Seremos su gorgojo (...)" (vv.12-13, p. 32). La intertextualidad con la Biblia continúa en el poema XXXVI al poetizar la resurrección de Lázaro. Se reconoce la importancia de la voz como transformadora del mundo, sin embargo, el hablante proyecta el desprecio del resucitado por el nombre de quien lo arrancó de la muerte.

El poema XXXIII funciona como una especie de cesura de Cuaderna oscura; es el texto más extenso del conjunto, impreso en páginas negras sobre las que destaca la tipografía blanca. Si bien no divide el libro en dos mitades exactas como la cesura de un verso alejandrino, la inversión del color de sus páginas y de la tipografía en relación con el resto del poemario producen un efecto de división, a la vez que se resalta el texto, denominado "Ortos". El término en sí une lo elevado y lo pedestre, puesto que remite a la aparición del Sol o de otro astro por el horizonte, y en lenguaje popular la palabra se emplea como sinónimo vulgar de ano. En el oscuro de la página, el yo se encuentra enmascarado pues, a semejanza de la escritura medieval o por evocación de un balbuceo, la enunciación se realiza en oraciones en tercera persona encabezadas con el pronombre relativo "que". En el poema se suceden diversos elementos que evocan tanto el imaginario medieval como el postmoderno: El yo se multiplica y se desdobla en yo-Maese, apela a "Vuesa Merced", discurre sobre Rabelais y Pasolini.

No se registran poemas con números XXXVII al XXXIX; el poema XL constituye una plegaria y a la vez una invitación para Dios, a sentarse a su mesa; la voz poética suplica por su liberación mental y espiritual, y pide perdón por la afrenta. El posible pecado es la palabra, cuya impronta es otro vacío, que abarca los inexistentes XLI hasta el XLIV. El texto XLV retiene la idea del pecado y de la culpa al poetizar el término "ramera" como un insulto proveniente de un contexto religioso, ya que se ha dicho ramera "En domingo de ramos" (v.7, p. 36). Es así como el texto transita desde la oración a la imprecación. 
El poema XLVI no existe en el libro, de esta forma el siguiente texto recibe el número XLVII y además el nombre "Lolita", una fallida historia de amor en la que late el deseo de olvido. La poetización del desamor también se percibe en el poema XLIX, en tanto se evoca una despedida amorosa. Entre estos textos, el poema XLVIII entrega una vista de la ciudad a partir del vidrio de un vaso, como una secuencia cinematográfica, en el que la lluvia es de vodka.

Nuevas reminiscencias bíblicas nos entrega el poema L, debido al deseo de lanzar una piedra contra alguien, anhelo imposible que se desvía hacia las futuras generaciones de quien se desea atacar. En el texto LI restos de destrucción y de muerte se utilizan para erigir una imagen religiosa. Previo a un gran vacío, el poema LII redunda en preguntas por la palabra y su lugar, tanto material como espiritual ¿es la boca, la pausa?, ¿los oráculos, las sibilas?, ¿el espanto? El sujeto de la enunciación se inclina por este último, por lo que reconoce que el lugar del poeta es un gran vacío, pues está llamado al silencio más que a la palabra.

El volumen cierra con el poema LX, dedicado al fallecido académico de la Universidad de Concepción, Juan Zapata Gacitúa. El texto poetiza a la literatura como un castillo medieval y al escritor como un penitente, vestido de "sayal prestado" (v.3, p. 43); el texto finaliza con un verso sin puntuación "Por eso trabajo" (v.16, p. 43), esta última palabra es sinónima de mester, pues este se considera un servicio. Zapata fue un estudioso de Enrique Lihn, el nexo implícito entre él y el autor de Cuaderna oscura. En La musiquilla de las pobres esferas de Lihn pululan una serie de imágenes como Bizancio, la semilla, el amor frío de los puertos, las hormigas, la alquimia del verbo de Rimbaud, que Herrera retoma en Cuaderna oscura; resalta, en especial, la alabanza del mester de juglaría de Lihn en el poema homónimo, mientras que en el poemario de Herrera se celebra la clerecía.

\section{Referencias}

Castro, J. (2007). Alfonso X el Sabio. Libro de los juegos: acedrex, dados e tablas. Ordenamiento de las tafurerías [1283]. Madrid. Fundación José Antonio de Castro. 
Eco, U. (2012). Arte y belleza en la estética medieval. Argentina: Random House Mondadori. S.A.

Herrera, J. (2018) Cuaderna oscura. Concepción: Ediciones Delarchivo.

La Biblia de nuestro pueblo. (2013). Bilbao, Ediciones Mensajero.

Lihn, E. (1969). La musiquilla de las pobres esferas. Santiago: Universitaria.

RAE, Real Academia Española. (1817). Diccionario de la Lengua Castellana. Quinta edición. Madrid: Imprenta Real.

Sepúlveda, G. (2018). Notas a la Cuaderna oscura de Juan Herrera. Recuperado de http://letras.mysite.com/gsep181118.html 